\title{
ОРГАНИЗАЦИЯ УЧЕБНОГО ПРОЦЕССА С ИСПОЛЬЗОВАНИЕМ ТЕХНОЛОГИЙ ДОПОЛНЕННОЙ РЕАЛЬНОСТИ
}

\section{ORGANIZATION OF THE EDUCATIONAL PROCESS USING AUGMENTED REALITY TECHNOLOGIES}

\section{O. Mnatsakanyan D. Eliseeva D. Agaltsova}

Summary: The article deals with the main issues of using augmented reality technologies in the educational process. The main directions of AR-technology in the educational sphere are given, as well as the characteristics of this technology are described. The structure of augmented reality applications that can be used in the educational process is given.

Keywords: information technologies, augmented reality, AR-technologies, software, educational process.

\author{
Мнацаканян Ольга Леонидовна \\ К.п.н., дочент, Российский государственный сочиальный \\ университет (2. Москва) \\ mnaolga@yandex.ru \\ Елисеева Дина Юрьевна \\ старший преподаватель, Российский государственный \\ сочиальный университет (2. Москва) \\ eliseeva.dy@mail.ru \\ Агальчова Дарья Владиславовна \\ К.п.н., дочент, Финансовый университет при \\ Правительстве Российской Федерачии, \\ darya_agaltsova@mail.ru
}

Аннотация: В статье рассматриваются основные вопросы использования технологий дополненной реальности в образовательном процессе. Приводятся основные направления AR-технологии в образовательной сфере, а также описываются характеристики данной технологии. Приведена структура приложений дополненной реальности, которую можно использовать в учебном процессе.

Ключевые слова: информационные технологии, дополненная реальность, AR-технологии, программное обеспечение, образовательный процесс.

Современные школьники, студенты обладают особым складом ума, способностью к восприятию информации в так называемом «клиповом» формате, т.е. через видеообразы, что активно формируют социальные сети, Интернет вне стен учебных заведений и, порой, еще до поступления ребенка в образовательное учреждение. Кроме того, становится все сложнее поддерживать вовлеченность в обучение студентов посредством бумажных текстовых учебников. Это создает необходимость перестраивать процесс обучения с учетом этих особенностей современных учеников. Становится очевидной необходимость интегрирования новых технологических решений и существующих методик обучения. Одним из таких инструментов является технология дополненной реальности (AR).

В настоящее время виртуальная и дополненная реальность считается одной из самых «взрывных» технологий. Создание виртуальной и дополненной реальности происходит посредством специальных программных средств. Дополненная реальность способна сделать восприятие информации человеком гораздо проще и нагляднее. Требуемые запросы будут автоматически доставляться пользователю. Принцип дополненной реальности заключается в совмещении виртуальных и существующих объектов в режиме реального времени [5]. Взаимодействие техники с изображением реального 
мира отличает дополненную реальность от виртуальной. В случае с дополненной реальностью, информация из окружающей действительности лишь частично дополняется виртуальным содержимым.

Дополненная реальность - это одна из самых перспективных технологий для использования в образовательной сфере [4]. Многие российские разработчики программного обеспечения уже предлагают свои решения в данной области на массовый рынок. Для массового внедрения данной технологии в большинстве учебных заведений необходимо решить ряд возникающих проблем.

1. Распространенность. Готовый программный продукт должен поддерживаться большинством актуальных устройств.

2. Стоимость. Готовый программный продукт должен быть доступен большому числу пользователей, следовательно, обладать низкой стоимостью.

3. Мобильность. Программный продукт может использоваться вне классных занятий, при домашней подготовке.

4. Компактность. Пользователь сможет выбрать удобный девайс, позволяющий с комфортом применять программный продукт в учебной деятельности.

Главной задачей дополненной реальности является увеличение возможностей пользователей, т.е. их взаимодействие с окружением, но уже на принципиально новом уровне. Данная технология позволяет с помощью компьютера или мобильного устройства создавать трехмерное окружение, которое, в дальнейшем, накладывается на объекты реального мира при помощи так называемых «маркеров» - изображений в реальном мире, к которым осуществляется привязка трехмерных объектов [5].

Несмотря на свои очевидные преимущества, технология дополненной реальности в образовании все еще не распространена не только в России, но и за рубежом. Основными сферами применения дополненной реальности в настоящее время являются:

1. сфера развлечений - используется в играх, видеотрансляциях;

2. сфера дизайна и строительства;

3. промышленность, в том числе оборонная.

Применительно к задачам образовательного процесса приложения дополненной реальности могут обеспечить:

- визуализацию учебной информации, что будет способствовать более успешному осознанию, запоминанию и усвоению учебного материала;

- доступность - обучающийся может применять приложение дополненной реальности как на занятиях в аудитории, так и при самостоятельной подготовке;
- эффект новизны даст возможность повысить заинтересованность обучающихся в освоении знаний, дополнительно мотивировать их.

Одним из определений, является то, что дополненная реальность (AR) - это интерактивная технология, которая позволяет дорисовывать «поверх» изображения с камеры 3d модели таким образом, что создается впечатление, что они непосредственно находятся в реальном мире [7].

Таким образом, можно выделить структуру приложений дополненной реальности, которая будет служить для моделирования или визуализации сложных процессов и предметов, состоящей из четырех основных модулей (рис. 1):

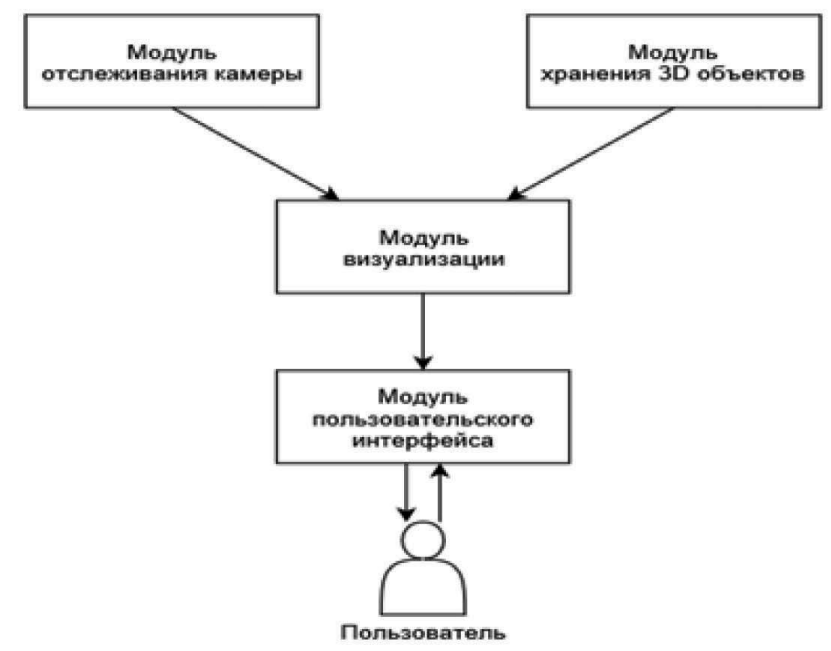

Рис. 1. Структура приложения дополненной реальности

1. модуль отслеживания камеры;

2. модуль хранения объектов;

3. модуль визуализации;

4. модуль пользовательского интерфейса.

Видеоизображение, полученное при помощи камеры устройства, передается в модуль отслеживания камеры. Данный модуль обрабатывает каждый полученный с камеры кадр:

- выполняет поиск установленного маркера,

- определяет положение маркера в реальном пространстве,

- на основе полученных данных вычисляет положение виртуальной камеры относительно маркера.

После того, как положение и ориентация камеры определенны, модулем хранения трехмерных объектов выбирается тот объект, который привязан непосредственно к рассматриваемому маркеру. Помимо этого, к 3D-модели применяются все установленные параметры размеров, масштаба, а также примененные на объект 
скрипты и иной код.

Далее происходит визуализация модели с использованием сдвига по отношению к расчетной позиции и согласованием с ориентацией. Пользователь может влиять на параметры модели и визуализации при помощи пользовательского интерфейса. Пользовательский интерфейс может быть представлен как в классическом виде (клавиши на мониторе компьютера или на экране мобильного устройства), так и в трехмерном пространстве, что позволяет пользователю взаимодействовать с интерфейсом в реальном мире, тем самым увеличивая погружение в процесс работы с программным продуктом.

Так же можно представить алгоритм работы программного продукта, использующего технологию дополненной реальности. В начале работы приложения происходит:

- инициализация камеры устройства,

- получение видеоизображения с данной камеры;

- выделение из потока отдельного кадра, для последующей работы с ним.

Далее на выделенном кадре происходит поиск маркера.

Если маркер найден, то происходит его опознание, в противном случае приложение выделяет новый кадр. Если приложению не удается опознать полученный маркер, то приложение снова возвращается к шагу получения кадра из видеоизображения. В случае успешного опознания полученного маркера происходит расчет преобразовании, на основе которых, происходит преобразование виртуальных объектов и позиционирование виртуальной камеры. Далее осуществляется визуализация виртуальных объектов поверх видеоизображения, полученного с камеры.
Работа приложения дополненной реальности включает в себя следующие основные компоненты.

1. Создание метки для привязки трехмерной модели.

2. Создание самой трехмерной модели.

3. Разработка скриптов для клавиш пользовательского интерфейса: «Уменьшение», «Увеличение», «Остановка вращения».

Создание трехмерных объектов, можно назвать одним из важнейших, т.к. именно разработанная модель будет выступать в качестве объекта, дополняющего реальность, от неё зависит новый формат восприятия реального мира. Для создания 3D-моделей используются различные 3D-редакторы и системы автоматизированного проектирования. Разработка модели, которой будет дополнена реальность, начинается с разбиения модели на отдельные элементы. Эти элементы называются примитивами. Создавая 3D-объект, можно добавлять такие примитивы как отверстия, полости, ребра, скругления. Все созданные элементы сохраняются в дереве модели. Оно содержит визуальную поэтапную запись последовательности действий, в которой создавалась твердотельная модель. Можно редактировать, переупорядочивать или удалять этапы процесса проектирования и спецификации, чтобы получить новую законченную деталь без повторного создания модели.

Таким образом, современные технологии дополненной реальности (AR) являются одной из самых перспективных технологий для использования в образовательной сфере, они позволяет визуально воспроизводить процессы, которые очень сложно или практически невозможно воссоздавать способами и средствами реального мира, тем самым делая процесс обучения более понятным и увлекательным.

\section{ЛИТЕРАТУРА}

1. Жигалова 0.П., Толстопятов А.В., Использование технологии дополненной реальности в образовательной сфере // Балтийский гуманитарный журнал. 2019. - T. 8. № 2(27) - C. 43-46.

2. Набокова Л.С., Загидуллина Ф.Р. Перспективы внедрения технологий дополненной и виртуальной реальности в сферу образовательного процесса высшей школы // Профессиональное образование в современном мире. 2019. Т. 9. № 2. С. 2710-2719. DOI: 10.15372/ PEMW20190208.

3. Уколов В.Ф. Цифровизация: взаимодействие реального и виртуального секторов экономики: монография / В.Ф. Уколов, В.В. Черкасов. - Москва: ИНФРА-М, 2019. -203 C.

4. Шелевер Л.В. Дополненная реальность в образовании - это миф или реальность? // European research: innovation in science, education and technology: XLI international scientific and practical conference. 2018. C. 31-35.

5. Budiman R.D.A. Developing learning media based on augmented reality (AR) to improve learning motivation // Journal of Education. 2016. vol. 1. № 2. pp. 89-94.

6. Mnatsakanyan 0.L., Altimentova D.Y., Agaltsova D.V. New educational results achieving by means of distance learning system. Human capital. $2017 ; 2: 19-21$.

7. Интерактивные технологии // Сайт компания EligoVision (000 «ЭлигоВижн») [Электронный ресурc] URL:.http://www.eligovision.ru/toolbox/about/

๑ Мнацаканян Ольга Леонидовна (mnaolga@yandex.ru), Елисеева Дина Юрьевна (eliseeva.dy@mail.ru),

Агальцова Дарья Владиславовна (darya_agaltsova@mail.ru).

Журнал «Современная наука: актуальные проблемы теории и практики» 